Contents List available at VOLKSON PRESS Intelligent Computing and Information Engineering (ICIE )

DOI : http://doi.org/10.26480/icie.01.2017.81.83

Journal Homepage: : https://www.intelcomp-design.com/

\title{
STUDY ON TOURIST SATISFACTION OF THE WAN-LV VALLEY RESORT BASED ON ONLINE COMMENTS
}

\author{
Yang Liang \\ College of Business Administration, He Yuan Polytechnic, Heyuan, Guangdong, 517000, China \\ *Corresponding author email: yangliang0219@163.com
}

This is an open access article distributed under the Creative Commons Attribution License, which permits unrestricted use, distribution, and reproduction in any medium, provided the original work is properly cited

\section{ARTICLE DETAILS}

\section{Article History:}

Received 12 May2017

Accepted 12 July 2017

Available online 14 September 2017

Keywords:

Online Comments, the Wan-lv Valley Resort, Tourist Satisfaction, Ecological Tourism.

\section{ABSTRACT}

Using the six OTA platforms, we collect the visitors' online comments on the Wan-lv valley resort and obtain valid data through identification, screening, induction and other means. Using ROST software analysis of high frequency words, vocabulary, text types, semantics, emotion, results show that visitors comment on Wan-lv valley resort focus on the tourism experience, ecological environment, tourism facilities, accommodation, price, landscape, traffic location and service. The two most important aspects of tourist comments are the tourist experience and the ecological environment, which are mainly positive evaluations. From the emotional semantic perspective, the tourists' comments on the Wan-lv valley resort mainly positive emotion. It shows that the quality of tourist experience is very high, and the probability of revisiting tourists is higher.

\section{INTRODUCTION}

In recent years, the development of tourism has gradually matured, although the market competition is more intense, but it is also more rational. Tourist operators pay more attention to tourist experience, while tourist satisfaction is an important index to measure their tourism experience quality. Tourist attractions satisfaction is the comprehensive psychological evaluation of the tourists' products or services to meet the needs of their tourism activities [1]. Study on tourist satisfaction has gradually attracted more attention, by the end of June 2017, CNKI library on the satisfaction of literature 12095, several aspects of domestic and foreign scholars mainly study the concept, tourist satisfaction measurement model, influence factors and satisfaction mean etc. In the era of mobile Internet, online reviews are the most important means for tourists to convey the experience of tourism to the outside world. This information has more and more influence on the tourism decisions of other tourists. Tourist online reviews are also the key factors in shaping and spreading tourist destination images [2].

\section{RESEARCH OBJECTS}

The Wan-lv valley resort is located in the southern section of Xinfeng river reservoir in Heyuan city, Guangdong province. The Xinfeng river reservoir is a reservoir area of 1, 600 square kilometers (1, 600 square kilometers) of the dam, which is built in the Yama mountain gorge in the lower reaches of Xinfeng River. In the valley of the lower reaches of the Xinfeng River, the dam is built to fill the water, thus forming the Xinfeng river reservoir, which has an area of 1600 square kilometer. Since the 1990s, the government has developed tourism in the Xinfeng reservoir, and began to call the Xinfeng river reservoir the Wan-lv Lake. Wan-lv valley resort is one of the many tourist areas around the lake, a total area of more than 30000 acres, its proximity to Nan Mountain, facing the green lake, wild animal species, lush vegetation, the growth of the primeval forest, ecological environment. The resort area consists of the original eco-tourism experience area and the Ye-wu resort area. The Tourism of Wan-lv valley resort has developed rapidly in recent years, the number of tourists increased steadily, and gradually formed a "primitive", "ecological" and "land of idyllic beauty" and "mysterious" tourism image.

\section{DATA COLLECTION}

In this paper, the data from the 6 OTA platform, including Tong Cheng, Ctrip, eLong, Qian-li Tu, Ma-feng Wo,Qunar, finally collect visitors comment on the Green Valley Resort 672, screened effective 567 comments. Because the main distribution platform of Wan-lv valley resort tourism products is Tong Cheng and elong, effective number of comments on these two sites totaling 505,

details are shown in table 1 :

Table 1: Major OTA and sample sizes

\begin{tabular}{|l|l|l|l|}
\hline OTA & sample sizes & OTA & sample sizes \\
\hline Ctrip & 24 & eLong & 275 \\
\hline Tong Cheng & 230 & Qunar & 2 \\
\hline Qian-li Tu & 11 & Ma-feng Wo & 25 \\
\hline
\end{tabular}




\subsection{Review Data Analysis}

According to the format requirements, we put the 567 comments into a text document, and then import the document into ROST statistical software to analyze and sort out and delete some words, then form the following high-frequency words. details are shown in table 2:

Table 2: characteristic words and frequency

\begin{tabular}{|l|l|l|l|l|l|l|l|}
\hline characteristic word & frequency & characteristic word & frequency & characteristic word & frequency & characteristic word & frequency \\
\hline very good & 352 & environment & 174 & Hotel & 150 & not bad & 96 \\
\hline good air & 94 & drift & 62 & good facilities & 50 & good service & 45 \\
\hline tickets & 42 & $\begin{array}{l}\text { Come } \\
\text { again }\end{array}$ & 41 & Leisure vacation & 39 & bumpy road & 39 \\
\hline fresh air & 38 & comfortable & 36 & funny & 36 & Kids love & 35 \\
\hline worth & 34 & happy & 34 & Villa & 32 & fine scenery & 32 \\
\hline clean & 31 & beauty spot & 31 & fantastic & 29 & recommend & 27 \\
\hline commonly & 26 & restaurant & 26 & expensive & 25 & quiet & 22 \\
\hline like & 19 & Inconvenient & 19 & satisfied & 18 & swimming & 18 \\
\hline Worth & 16 & beautiful & 15 & bad & 13 & poor & 13 \\
\hline scenery & 13 & relax & 13 & natural & 12 & restroom & 12 \\
\hline First-rate & 12 & delicious & 11 & characteristic & 11 & Resort & 11 \\
\hline ecology & 10 & Far away & 10 & pleasure & 10 & Green & 9 \\
\hline great & 9 & partial & 9 & quiet & 9 & glad & 8 \\
\hline cheat & 8 & streams & 8 & cost-effective & 8 & cheap & 7 \\
\hline
\end{tabular}

Tourists comment high-frequency words are "good" and "good environment", "Hotel", "drifting", "good facilities" , "good service", "leisure", "fun", "beautiful scenery", that visitors comment on the Wan-lv valley resort is mainly positive, more satisfied with their travel experience.

Through the analysis of the characteristics of all high-frequency words, it is found that the description objects are mainly concentrated in 8 aspects: tourism experience, ecological environment, tourist facilities, accommodation, cost performance, landscape, location, traffic and service. The tourist experience and eco-environment have a total of 1,099 high frequencies, accounting for 54.3 percent, which indicates that visitors are very fond of the ecological environment of the green valley and have a high tourist experience. Tourist facilities and services have 435 high frequencies, accounting for 21.5 percent. In addition, many tourists comment on location, traffic and landscape of the resort.

Table 3: the type distribution of high frequency feature words

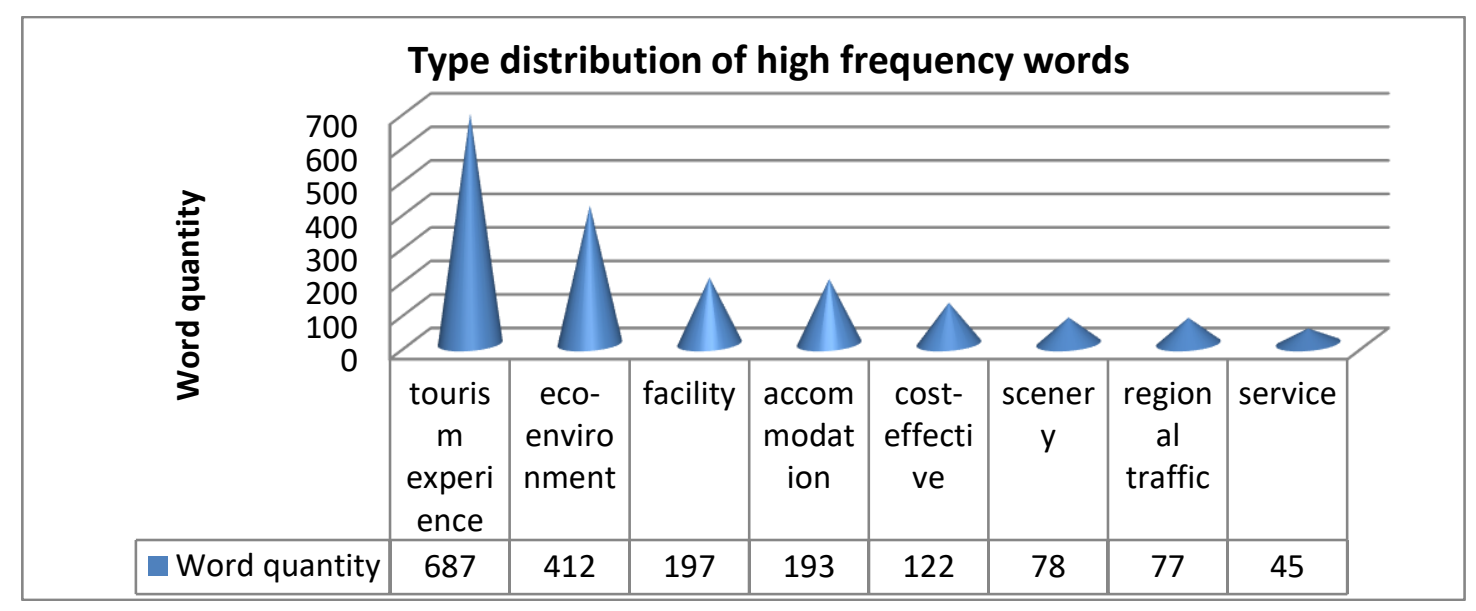

\subsection{Sentiment analysis of tourist comment texts}

Text sentiment analysis, also known as the "opinions" of subjective text mining, is with emotional processing, analysis, induction and reasoning process. Sentiment analysis is derived from the previous analysis of early emotional color words [3]. The sentiment analysis of visitors' online comments can effectively reflect the tourists' attitudes and impressions about the tourist destination. Through the sentiment analysis of Wan-lv valley resort Network text, results showed that the proportion of tourists on the Wan-lv valley positive emotion is $74.2 \%$, neutral emotion is $18.4 \%$, negative emotion is $7.4 \%$. The proportion of positive emotions was very high, the proportion of highly positive emotions was $49.5 \%$, and the proportion of moderate positive emotions reached $28.4 \%$. The above analysis not only shows that tourists are highly satisfied with tourism, but also have the possibility to translate into emotional support.

Negative mood is very low, only 7.4\%, tourist's comments is "rugged" and "convenience", "remote" and so on, mainly because of the Wan-lv valley resort is located in the deep of lake area, so it is only retaining its original ecological environment. Because of the need for ecological protection, large-scale tourism development is limited.

Table 4: Emotional analysis of high frequency words

\begin{tabular}{|c|c|c|l|l|l|}
\hline Emotion types & Word quantity & Proportion & strength & Word quantity & Proportion \\
\hline Positive emotion & 1501 & 74.2 & general & 332 & 22.1 \\
\cline { 4 - 7 } & & & Moderate & 426 & 28.4 \\
\cline { 4 - 7 } & & & Highly & 743 & 49.5 \\
\hline Neutral emotion & 372 & 18.4 & & & \\
\hline Negative emotion & 150 & 7.4 & general & 29 & 19.3 \\
\hline
\end{tabular}




\begin{tabular}{|l|l|l|l|l|l|}
\hline & & & Moderate & 48 & 32.0 \\
\cline { 4 - 6 } & & & Highly & 73 & 48.7 \\
\hline Total & 2023 & 100 & & & \\
\hline
\end{tabular}

\section{CONCLUSIONS}

Based on statistical network text, the visitor network comments on the Wan-lv valley resort are mainly "very good" and "good environment", "fresh air", "drift" and "bumpy road", "leisure", "fun", and "beautiful scenery" words, which shows that visitors comment on the green valley is mainly positive, the tourism experience is satisfactory.

Visitors' comments mainly focus on 8 aspects: tourist experience, ecological environment, tourist facilities, accommodation, cost performance, landscape, location, traffic and service. Two most of the visitors to comment is tourism experience and the ecological environment, which shows that tourists have a very deep impression on the original ecological environment of the Wan-lv valley resort. with green "ecological" and "Green Valley" and "uncharted" tourism image.

The results are consistent with the Wan-lv valley resort image of "ecology", "green valley" and "secret territory".

Tourist comments on the Wan-lv valley resort are mainly positive emotion, which can judge the possibility of revisiting. Finally, these tourists will be constructed and disseminators of Wan-lv valley resort image.

The quality of tourist experience is the basis of sustainable development of tourism products. In the mobile Internet era, the rapid development of the media can help visitors to express their travel experience at any time and place, and this phenomenon is more and more to influence of many potential visitors, because of this experience from consumer groups look like very real. To some extent, the market reaction caused by this kind of behavior has even exceeded the effect of advertisement.

For scenic managers, positive reviews and positive emotions of tourist are critical. Superior ecological environment and tourism products of Wan-lv valley resort beyond the expectations of most visitors, so the tourist satisfaction is higher. The managers of scenic spots should balance the environmental benefits, economic benefits and social benefits, and avoid the ecological environment of the resort by excessive pursuit of benefits.

\section{REFERENCES}

[1] Nan, J. 2008. Fuzzy Comprehensive Evaluation Method of Tourist Satisfaction Degree in Scenic Spots, Social Scientist, 92-94.

[2] Ying, Z. 2016. An image perception research on ecotourism destination under the Internet word of mouth and horizon Take Wanlv Lake scenic spot in Guangdong as an example. Tourism Research, 63-68.

[3] Yan-Yan, Z., Bing, Q., Ting, L. 2010. Sentiment Analysis. Journal of Software, 21 (8), 1834-1848. 